\title{
Romance e Discurso Considerações sobre algumas das ideias de Mikhail Bakhtin ${ }^{1}$
}

\author{
Novela y Discurso Consideraciones sobre algunas ideas de Mijail
}

Bajtín

Novel and Discourse Considerations on some of the ideas of Mikhail

\author{
Bakhtin
}

Margarete Hülsendeger ${ }^{2}$

\begin{abstract}
Resumo
Neste artigo serão apresentadas algumas das ideias de Mikhail Bakhtin explicitadas em quatro de suas obras mais importantes: Estética da Criação Verbal (1979), Problemas da poética de Dostoiévski (1929), A cultura popular na Idade Média e no Renascimento (1965) e Questões de literatura e de estética (1975). O objetivo é mostrar como os conceitos de polifonia e carnavalização são por ele apresentados e como elaborou sua concepção de literatura, partindo da ideia de gênero, considerando-a, em essência, um discurso no qual todo o signo é motivado e, portanto, ideológico. Nessa apresentação também será possível perceber como nessas obras há uma continuidade temática cuja proposta está ligada a construção de sua teoria sobre o romance.
\end{abstract}

Palavras-chave: Mikhail Bakhtin; Discurso; Gênero; Romance.

\section{Resumen}

En este artículo se presentarán algunas de las ideas de Mijaíl Bajtín explicitadas en cuatro de sus obras más importantes: Estética de la creación verbal (1979), Problemas de la poética de Dostoievski (1929), La cultura popular en la Edad Media y el Renacimiento (1965) y Problemas literarios y estéticos (1975). El objetivo es mostrar como los conceptos de polifónico y carnavalización son por él presentados y cómo elaboró su concepción de literatura, a partir de la idea de género, considerándola, en esencia, un discurso en el que todo el signo es motivado y, por lo tanto, ideológico. En esta presentación también será posible percibir cómo en esas obras hay una continuidad temática cuya propuesta está ligada a la construcción de su teoría sobre la novela.

Palabras claves: Mijail Bajtín; Discurso; Género; Novela.

\begin{abstract}
In this paper will be presented some of Mikhail Bakhtin's ideas in four of his most important works: Esthetics of verbal creation (1979), Problems of poetics by Dostoevsky (1929), Popular culture in the middle ages and the renaissance (1965) and Questions of Literature and Aesthetics (1975). The objective is to show how the concepts of polyphony and carnivalization are presented by him and how he elaborated his conception of literature, starting from the idea of genre, considering it in essence a discourse in which the whole sign is motivated and therefore ideological. In this presentation it will also be possible to see how in these works there is a thematic continuity whose proposal is linked to the construction of his theory about the novel.
\end{abstract}

\footnotetext{
${ }^{1}$ O presente trabalho foi realizado com apoio da Coordenação de Aperfeiçoamento de Pessoal Nivel Superior Brasil (CAPES) - Código de Financiamento 001 [This study was financed in part by the Coordenação de Aperfeiçoamento de Pessoal de Nivel Superior - Brasil (CAPES) - Finance Code 001].

${ }^{2}$ Mestra em Teoria da Literatura/PUCRS, doutoranda em Teoria da Literatura/PUCRS (Bolsista CAPES). Email: margacenteno@gmail.com.
} 
Keywords: Mikhail Bakhtin; Discourse; Genre; Novel.

Tzvetan Todorov no Prefácio de Estética da Criação Verbal, define Mikhail Bakhtin (1895-1975) como "uma das figuras mais fascinantes e enigmáticas da cultura europeia do século XX” (TODOROV In BAKHTIN, 1997, p. 01). Ao longo dessa apresentação, Todorov aponta uma série de aspectos que fundamentariam, não só o interesse pela figura de Bakhtin, como também o seu pensamento: a crítica dirigida aos formalistas, a substituição da ideia de absoluto pela de relatividade generalizada - semelhante "à de Einstein, no plano do conhecimento do mundo físico (TODOROV In BAKHTIN, 1997, p. 08) -, o empenho em avançar de uma análise puramente linguística para uma análise translinguística - cujo objeto seria a interação verbal -, a presença da história na análise literária e a constatação de que a literatura sempre joga com uma multiplicidade de vozes, presentes na consciência daqueles que falam.

Esses aspectos do pensamento bakhtiniano, mencionados por Todorov, podem ser percebidos, não só na Estética da Criação Verbal (publicado em 1979), mas em três outras obras: Problemas da poética de Dostoiévski (publicada originalmente em 1929, tendo sido reeditada em 1963, de forma bastante modificada), A cultura popular na Idade Média e no Renascimento (concluído em 1940, mas publicado em 1965) e Questões de literatura e de estética (publicado em 1975, o ano de sua morte). Bakhtin, utilizando como modelos as obras de Dostoiévski e Rabelais, além de apresentar conceitos fundamentais que comporiam seu corpus teórico - polifonia, plurilinguismo, carnavalização e dialogismo -, expõe sua concepção de literatura, partindo da ideia de gênero e do fato de considerá-la, em essência, um discurso no qual todo o signo é motivado e, portanto, ideológico. Ademais, ao retomar muitas de suas ideias, percebe-se uma continuidade temática cujo objetivo é construir sua teoria sobre o romance; uma teoria que, ao ser comparada com outras teorias literárias, se mostra mais abrangente e flexível, uma vez que incorpora ao seu discurso diferentes vozes e estilos ${ }^{3}$.

Para entender as ideias de Bakhtin sobre o romance é preciso primeiro compreender seu conceito de gênero. Para ele, os gêneros permanecem ao longo do tempo, constituindo-se uma tradição. Contudo, essas formas não se mantêm intocáveis, elas se transformam, na

\footnotetext{
${ }^{3}$ Com essa observação não se pretende dizer que a teoria sobre o romance de Bakhtin é melhor (ou pior) que outras teorias literárias. O propósito é apenas destacar duas de suas características mais importantes: a abrangência e a flexibilidade.
} 
maioria das vezes, ao sabor das circunstâncias sociais, políticas e econômicas. E são essas constantes atualizações (ou transformações) que têm garantido a sua sobrevivência. Assim, o conceito de gênero literário é, segundo Bakhtin (1981), simultaneamente, novo e velho, pois vive no presente, recordando o seu passado. Para Bakhtin, o gênero é o "representante da memória criativa no processo de desenvolvimento literário. É precisamente por isto que tem a capacidade de assegurar a unidade e a continuidade desse desenvolvimento" (BAKHTIN, 1981, p. 91, grifos do autor).

Tendo como base esse conceito, o crítico russo analisa aquele que ele considerava uma das raízes do romance: o gênero cômico-sério. Conforme Bakhtin (1981), há nesse gênero uma forte relação com o folclore carnavalesco, no qual palavra e imagem encontram-se em uma relação especial com a realidade, baseada na experiência, na fantasia e na diversidade de estilos e de vozes. Desse modo, os elementos carnavalescos ajudariam a remover as barreiras entre os gêneros, entre sistemas fechados de pensamento e entre diferentes estilos, aproximando e unificando unidades distantes e dispersas. A partir dessas peculiaridades, próprias do gênero cômico-sério, surge o que Bakhtin denominou "literatura carnavalizada" ou seja, uma literatura que, "direta ou indiretamente, através de diversos elos mediadores, sofreu a influência de diferentes modalidades de folclore carnavalesco (antigo ou medieval) (BAKHTIN, 1981, p. 92).

A partir da caracterização do gênero cômico-sério, Bakhtin constrói o seu conceito de gênero romanesco, transformando-o em um fenômeno plurilinguístico, plurilíngue e plurivocal, submetido a leis estilísticas distintas e apoiando-se em planos linguísticos diferentes. Nesse sentido, ele vê no romance a presença de uma diversidade social de linguagens que admite introduzir na sua composição diferentes gêneros literários e extraliterários. O romancista pode, então, recorrer a todo o tipo de linguagem para orquestrar os seus temas, refletir suas ideias e julgamentos de valor. $\mathrm{O}$ aprofundamento das diferentes vozes também permite ao escritor construir um estilo próprio, mantendo a unidade da sua personalidade e impedindo que a linguagem se torne um meio neutro (BAKHTIN, 1990).

Uma questão importante, posta em evidência por Bakhtin, é a necessidade de compreender que um gênero com características tão particulares não pode ser explicado pela estilística tradicional, pois como ela não sabe abordar o diálogo social acaba sempre optando por duas substituições: a simples descrição da linguagem do romancista ou o destaque de um dos estilos subordinados, analisando-o como estilo do todo (BAKHTIN, 1990). Assim, quando descreve a linguagem do romancista, essa estilística tradicional ressalta o estilo do gênero e da obra, que passa a ser examinado como fenômeno da própria linguagem. Como 
consequência o estilo é compreendido como uma individualização da língua geral que, sendo imprecisa, deforma a própria essência da estilística romanesca. O estilo do romance fica, então, reduzido ao conceito de "estilo épico", desconsiderando-se a profunda diferença entre a representação épica e a romanesca (BAKHTIN, 1990). Bakhtin ressalta também que toda a concepção filosófica sobre a qual repousa o discurso épico não pode conter o discurso da prosa literária romanesca. Logo, é preciso rever as concepções filosóficas sobre o discurso poético para reconhecer o romance e aponta como uma possível solução para essa problemática a retórica.

Uma análise semelhante pode ser aplicada ao discurso do pensamento estilístico tradicional. Segundo Bakhtin (1990), esse tipo de discurso conhece apenas a si mesmo e como é neutro não pertence a ninguém. No entanto, qualquer discurso não se coloca da mesma maneira diante do seu objeto, pois ele está impregnado por conceitos, perspectivas, apreciações e entonações dos outros. Desse modo, para o romancista, o objeto acaba revelando a multiformidade social plurilíngue dos seus nomes, definições e avaliações (BAKHTIN, 1990). Em suma, a dialogicidade interna da prosa literária, penetrando na ideia e na expressão do objeto do discurso, torna-se um dos aspectos essenciais do estilo prosaico e, portanto, do romance.

Nesse sentido, Bakhtin enumera as características do prosador-romancista: (1) acolhe as diferentes falas e linguagens contribuindo para que se tornem mais profundas, (2) constrói seu estilo, mantendo a unidade de sua personalidade de criador, (3) não purifica seus discursos das intenções e tons de outros, (4) não destrói os germes do pluringuismo social, (5) pode usar a linguagem sem se entregar totalmente a ela, (6) não destrói as perspectivas sócioideológicas e, (7) utiliza discursos já povoados pelas intenções dos outros (BAKHTIN, 1990, p. 104-105). Para exemplificar essas ideias Bakhtin toma como modelo Dostoiévski (18211881), pois vê em sua obra uma forte presença de um discurso dialógico, com muitas vozes, enquanto na maioria dos romances ouve-se apenas uma voz (um discurso monológico).

As vozes dos personagens de Dostoiévski são autônomas, ideologicamente diferentes e, portanto, em permanente conflito. A esse processo Bakhtin dá o nome de "polifonia". Segundo Irene Machado, o escritor russo não elabora um conceito exato para polifonia; na verdade, "tal conceito se desenvolve no conjunto de sua análise do romance como representação do homem que fala e discute ideias, numa produção bivocalizada da imagem linguagem, ou seja, nos limites do diálogo" (MACHADO, 1995, p. 132). Do mesmo modo, a autora explica que Bakhtin reconhecia que a polifonia não era uma qualidade de todo o 
romance, mas, que "foi Dostoiévski quem realizou a polifonia pela primeira vez em seus romances (MACHADO, 1995, p. 132).

Bakhtin acreditava que o discurso polifônico de Dostoiévski tinha sua origem na sátira menipeia. No entanto, ele observa que não se tratava da menipeia antiga, mas particularidades desse gênero que foram renovadas e reatualizadas por Dostoiévski. O romancista russo, não foi, um

estilizador de gêneros antigos. Dostoiévski se juntava à cadeia de uma dada tradição de gêneros naqueles lugares em que ela lhe transpassava a atualidade, embora os elos do passado dessa cadeia, inclusive o elo antigo, lhe fossem, em diferentes graus, bem conhecidos e próximos. Em termos um tanto paradoxais podemos dizer que quem conservou as particularidades da menipéia antiga não foi a memória subjetiva de Dostoiévski mas a memória objetiva do próprio gênero com o qual ele trabalhou (BAKHTIN, 1981, p. 104, grifo do autor).

$\mathrm{Na}$ menipeia tudo está subordinado ao ato de criar situações extraordinárias para provocar e experimentar uma ideia filosófica. Além disso, está presente um naturalismo que tem sua origem no mundo das camadas mais baixas da sociedade, permitindo que se apresente o homem e a vida na sua totalidade. Surge, a partir da sátira menipeia, o fantástico experimental com a representação de estranhos estados psicológicos-morais do homem. Há, também, a presença de diversas violações do universalmente aceito e comum, incorporando, muitas vezes, elementos da utopia social, assim como, o amplo emprego de gêneros de fusão dos discursos da prosa e do verso.

É com esses conceitos em mente que Bakhtin analisa algumas das obras de Dostoiévski. De acordo com Machado, com o objetivo de mostrar Dostoiévski em Dostoiévski, Bakhtin examina "os meios de visão e de representação artística dentro do romance, dentro da construção artística, e não dentro da cosmovisão ou da vida do autor" (MACHADO, 1995, p. 141). Assim, no conto Bobok (1873), Dostoiévski constrói discursos dialogados e polêmicos, com a presença da familiarização e profanação, do naturalismo, do fantástico e de um acentuado tom carnavalesco (BAKHTIN, 1981). Já em $O$ sonho de um homem ridículo (1877), Dostoiévski revela a capacidade de perceber e sentir artisticamente, concentrando a ação nos pontos das crises, reviravoltas e catástrofes, sempre vinculado à imagem do limiar ou da praça pública (BAKHTIN, 1981). E em As memórias do subsolo (1864) aparece com força a diatribe, a profanação, o naturalismo do submundo e uma excepcional capacidade ideológica (BAKHTIN, 1981).

Aproveitando os elementos característicos da menipeia, atualizados por Dostoiévski, Bakhtin introduz outro importante conceito da sua teoria, a "carnavalização". Conceito que, 
mais tarde, ele aprofunda quando realiza a análise da obra de François Rabelais (1494-1553). $\mathrm{Na}$ literatura, as formas carnavalescas tornaram-se poderosos meios de interpretação artística da vida, apresentando uma linguagem com força de generalização simbólica que permite uma transposição das características existentes no carnaval para a linguagem literária.

De acordo com Bakhtin (1981), no carnaval todos participam da ação carnavalesca, vivendo uma "vida às avessas". Desse modo, a visão do mundo está alterada, permitindo a existência de um segundo mundo e uma segunda vida, gerando uma espécie de ambivalência. Durante as festividades do carnaval elimina-se a distância entre os homens e, consequentemente, a hierarquia deixa de existir, dando espaço para as chamadas "ações carnavalescas", como a coroação bufa e o destronamento do rei do carnaval. Os símbolos carnavalescos também incorporam a perspectiva da negação (a morte) e as imagens são, geralmente, biunívocas: mudança e crise, nascimento e morte, benção e maldição, etc. $\mathrm{O}$ "princípio cômico" (BAKHTIN, 1987) está livre de qualquer dogmatismo religioso ou de qualquer caráter mágico, não existindo fronteiras físicas e suas leis sendo as leis da liberdade. Trata-se de uma "vida festiva" (BAKHTIN, 1987) e o "riso carnavalesco" - elemento importante dentro da obra de Dostoiévski e de Rabelais - é ambivalente, assumindo uma posição estética, um método de interpretação da realidade com enorme força criativa, pois, diferente do riso satírico moderno, o riso carnavalesco não destrói a integridade do aspecto cômico do mundo. Uma diferença que também pode ser percebida quando se compara a sátira e a paródia, pois enquanto a primeira é demolidora, a segunda traz o modelo e o reinventa, iluminando-o.

O carnaval acaba, então, criando uma linguagem própria que se caracteriza pela lógica original das coisas "ao avesso", das permutações constantes do alto e do baixo, da face e do traseiro, dos coroamentos e destronamentos bufões (BAKHTIN, 1987). Essas novas formas linguísticas contribuem para o estabelecimento de um ambiente de liberdade no qual a linguagem familiar torna-se um reservatório em que se acumulam expressões verbais proibidas. Há também um amplo emprego de gêneros e fusão dos discursos da prosa e do verso com a incorporação de gêneros cognatos, a diatribe, o solilóquio e o simpósio, esse último sendo o diálogo dos festins e, portanto, um gênero puramente carnavalesco.

Contudo, assim como nem todo o discurso bivocalizado garante a polifonia, pois ela surge pela "total ausência de um ponto de vista autoral dominante" (MACHADO, 1995, p. 132), a carnavalização também não garante um discurso dialógico ou polifônico. Em outras palavras, a obra pode apropriar-se de elementos carnavalescos e o discurso ser monológico. Por isso, conforme Machado (1995), o próprio Bakhtin reconhecia que a polifonia não era 
uma qualidade de todo o romance - Dostoiévski seria o criador do romance polifônico - pois, na verdade, ela marca um posicionamento fora do comum do autor no romance. Essa ideia levou Bakhtin a ver o romance como um gênero incompleto que surge para "representar o presente em toda a sua instabilidade, inacabamento e evolução" (MACHADO, 1995, p. 140).

Os conceitos de "inacabamento", "instabilidade" e "evolução" permitem que Bakhtin introduza na sua concepção de romance o homem, ou seja, o personagem. Para ele, todas as formas de transmissão da palavra do outro são representadas e reproduzidas nos enunciados familiares e ideológicos dos personagens. Como consequência, o homem no romance é basicamente o homem que fala, pois, o romance necessita de falantes que lhe tragam o seu discurso (BAKHTIN, 1990), e a palavra, para que tenha penetração dialógica, não pode ser objetivada e coisificada. Do mesmo modo, não se pode separar a palavra da realidade porque, nesse caso, ela perde profundidade semântica e mobilidade, isto é, ela morre enquanto palavra (BAKHTIN, 1990). Por essa razão, a diferença entre o herói épico e o do romance é que o segundo não apenas age, mas também fala e sua ação não tem um significado geral e indiscutível.

Em vista disso, todos os componentes de uma obra "nos são dados através da reação que eles suscitam no autor" (BAKHTIN, 1997, p. 26), abrangendo "tanto o próprio objeto quanto a reação do herói ao objeto" (BAKHTIN, 1997, p. 26). O discurso dos personagens, no centro do romance polifônico, mantém, então, uma equivalência com o discurso do autor, de tal maneira que entre os dois (autor e personagem) estabelece-se uma relação de horizontalidade. Nesse sentido, o herói do romance de Dostoiévski é capaz de revelar

muitos disfarces, máscaras aleatórias, gestos falsos, atos inesperados que dependem das reações emotivo-volitivas do autor; este terá de abrir um caminho através do caos dessas reações para desembocar em sua autêntica postura de valores e para que o rosto da personagem se estabilize, por fim, em um todo necessário. [...]. O artista que luta por uma imagem determinada e estável de um herói lutar, em larga medida, consigo mesmo (BAKHTIN, 1997, p. 26-27).

Para exemplificar esses conceitos, Bakhtin vale-se de sua análise da obra de Dostoiévski, apontando que o "herói" do autor russo não é e nem pode ser personificado, e é por isso que ele não assume um "comportamento bem-educado" (BAKHTIN, 1981), como ocorre com o herói do romance de aventura. O personagem, para Bakhtin, é um indivíduo que representa sempre um ponto de vista particular sobre o mundo, personificado em sua ação e palavra. Por isso, ao analisar as obras de Dostoiévski, ele diz que nele não iremos encontrar 
motivos como "“isto eu não vi', 'disto eu não sabia', 'isso só me foi revelado mais tarde"”, pois, seu "herói sabe de tudo e tudo vê desde o começo" (BAKHTIN, 1981, p. 210).

Outro aspecto importante do pensamento bakhtiniano é a preocupação historiográfica. Ao analisar a obra de François Rabelais ele transita pela Idade Média e o Renascimento com o objetivo de demonstrar que as imagens rabelaiseanas só podem ser compreendidas a partir de um exame da cultura popular desses dois períodos, discernindo suas dimensões e definindo suas características originais (BAKHTIN, 1987). Com essa justificativa ele estabelece uma ponte entre essas imagens e um estudo profundo das suas fontes populares, afirmando que o "aspecto não-literário" da obra de Rabelais estaria na origem da resistência de ajustá-la aos cânones vigentes desde o século XVI até os dias de hoje.

Quando o crítico russo examina a cultura popular da Idade Média e do Renascimento, para assim entender as imagens rabelaiseanas, ele está realizando uma análise das características do chamado "realismo grotesco" (BAKHTIN, 1987, p. 17). De acordo com ele, no realismo grotesco

(isto é, no sistema de imagens da cultura cômica popular), o princípio material e corporal aparece sob a forma universal, festiva e utópica. O cósmico, o social e o corporal estão ligados indissoluvelmente numa totalidade viva e indivisível. É um conjunto alegre e benfazejo (BAKHTIN, 1987, p. 17).

Assim, para Bakhtin (1987), a presença de imagens cômicas associadas ao carnaval foi o que deu origem ao realismo grotesco. Nele, o princípio material e corporal aparece sob a forma universal, festiva e utópica, ligado a uma totalidade viva e indivisível, com um riso que degrada e materializa. No entanto, Bakhtin explica que o significado de "degradar" utilizado na Idade Média é diferente do conceito moderno: no medievo, implicava entrar em comunhão com a parte inferior do corpo, aproximar-se da terra; hoje, assume um aspecto negativo, tendo relação com o tornar-se abjeto e indigno. Do mesmo modo, ao contrário dos cânones modernos, o corpo, no realismo grotesco, é sempre de uma idade próxima ao nascimento ou à morte. Bakhtin, então, recomenda que esse (ou qualquer outro) cânone seja julgado dentro de seu próprio sistema, pois o termo "cânone" deve ser interpretado no sentido mais amplo, vendo-o como uma forma dinâmica e em processo de permanente desenvolvimento.

A análise historiográfica empreendida por Bakhtin permite que se perceba as transformações pelas quais passou, ao longo do tempo, o conceito de grotesco. No século XVII ele demonstra a existência de uma redução, falsificação e empobrecimento dos ritos e espetáculos carnavalescos populares, de forma que a concepção carnavalesca do mundo e o 
sistema de imagens grotescas continuam vivendo apenas na literatura; no século XVIII, com as mudanças no campo literário e estético, volta-se a perguntar se é possível admitir o grotesco; e, no romantismo, o grotesco ressurge na forma de uma visão de mundo subjetiva e individual, um grotesco de câmara, onde o riso se atenuou e tomou a forma de humor, ironia ou sarcasmo. Portanto, enquanto na literatura do Renascimento encontra-se uma visão própria da cosmovisão carnavalesca, característica do gênero grotesco dessa época, nos romances sociais do século XIX há uma carnavalização mais exterior e, portanto, menos profunda e livre. Contudo, Bakhtin reconhece que o romantismo fez um descobrimento importante, ou seja, descobriu o indivíduo subjetivo, profundo, íntimo, complexo e inesgotável (BAKHTIN, 1987).

Retomando as palavras de Todorov no seu Prefácio para a Estética da Criação Verbal, pode-se dizer que as ideias de Bakhtin se assentam sobre um sentido de liberdade no qual a interpretação é o seu exercício (TODOROV In BAKHTIN, 1997, p. 20). Sua visão do romance pressupõe essa liberdade de interpretação, pois nela há a possibilidade de línguas de diversas épocas e de períodos da vida sócio-ideológica poderem coexistir em completa harmonia sem se excluírem, cruzando-se de diversas maneiras. Por esse motivo, o romance é um hibrido que tem o propósito de criar uma imagem viva de uma outra linguagem, de forma que não há apenas uma mistura de formas e indícios de duas linguagens e estilos, mas um choque no interior dessas formas, dos pontos de vista sobre o mundo. O discurso dialógico e polifônico, o plurilinguismo são recursos que não permitem uma imitação do exterior, nem a sua simples reprodução, mas um desenvolvimento criativo em um contexto e condições novas. O romance torna-se, portanto, um modo de representação que se apropria do mundo e fala com ele, um gênero que, na visão de Bakhtin, não tem uma semântica terminada, permanecendo aberta, orientada para o homem contemporâneo e para um descendente, como "se fosse um contemporâneo".

\section{Referências}

BAKHTIN, Mikhail. Problemas da poética de Dostoiévski. Tradução Paulo Bezerra. Rio de Janeiro: Forense-Universitária, 1981.

BAKHTIN, Mikhail. A cultura popular da Idade Média e no Renascimento: o contexto de François Rabelais. Tradução Yara Frateschi Vieira. São Paulo: HUCITEC; Brasília: UNB, 1987. 
BAKHTIN, Mikhail. Questões de literatura e estética: a teoria do romance. Equipe de tradução: Aurora Fornoni Bernadini José Pereira Júnior Augusto Góes Júnior Helena Spryndis Nazário Homero Freitas de Andrade. São Paulo: HUCITEC/UNESP, 1990.

BAKHTIN, Mikhail. Estética da criação Verbal. Tradução diretamente do francês por Maria Ermantina Galvão G. Pereira. Revisão Marina Appenzeller. São Paulo: Martins Fontes, 1997 (Coleção Ensino Superior).

MACHADO, Irene A. O romance e a voz: a prosaica dialógica de Mikhail Bakhtin. Rio de Janeiro: Imago; São Paulo: FAPESP, 1995.

TODOROV, Tzvetan. Prefácio. In: Estética da criação Verbal. Tradução diretamente do francês por Maria Ermantina Galvão G. Pereira. Revisão Marina Appenzeller. São Paulo: Martins Fontes, 1997 (Coleção Ensino Superior). 